\title{
Research on Cross-Cultural Management of Sino- African Cooperative Enterprises From the Perspective of Cultural Differences
}

\author{
Ping Wang ${ }^{1, *}$ and Lu Wang ${ }^{1}$ \\ ${ }^{1}$ Department of Economics and Management, Zhejiang Sci-tech University, Hangzhou, Zhejiang 310000, China \\ *Corresponding author.Email: wp190923@163.com
}

\begin{abstract}
Based on Hofstede's cultural dimensions theory and used the method of literature comparison, this paper analyzes and deeply excavates the cultural differences between China and Africa from Hofstedt's six cultural dimensions, and studies and summarizes the five major differences in employee behavior and management in cross-cultural management between Sino-African cooperative enterprises, including organizational communication, operation mode, ideology, management behavior and human resource management. It points out that six common problems existing in today's Sino-African cooperative enterprises, such as the conflict of management mode, the problem of human resource management, the difficulty of decision-making and implementation, staff cooperation, and avoiding cognitive differences. In order to solve these problems, this research proposes 5 countermeasures: understand and respect cultural differences, carry out diversified training activities, strengthen cross-cultural communication among employees, optimize human resource management system, implement the talent localization strategy.
\end{abstract}

Keywords: Sino-African cooperative enterprises, cultural differences, cross-cultural management, Hofstede's cultural dimensions theory

\section{INTRODUCTION}

Under the background of "The Belt and $\operatorname{Road}(B \& R) "$, China and African countries cooperative relations are increasingly close. On the occasion of the 20th anniversary of the establishment of the Forum on China Africa Cooperation (FOCAC), the sudden outbreak of Covid-19 has brought great impact on African economy. In June 2020, President Xi Jinping presided over the special summit of China Africa solidarity against epidemic diseases, and pointed out that it was necessary to unswervingly support and help Africa resume work and production and recover the economy. As an important link of economic and cultural transmission between China and Africa, Sino-African cooperative enterprises need to strengthen internal construction and stabilize their own conditions in order to cope with the unpredictable external environment. Culture internalized in employees, reflected in their behavior, and then affected enterprise management and performance. In recent years, labor conflicts between China and Africa have occurred frequently [1]. For example, the violent wage claim incident of African employees in Tanzania friendship textile factory in 2016 can be attributed to the huge cultural differences between China and Africa in terms of values and thinking modes. Based on the classical theory and from the perspective of cultural differences, this paper explores the current situations of cross-cultural management of Chinese and African enterprises, and makes a comparative analysis of employees' behaviors and management differences between China and Africa, which will help Sino-African cooperative enterprises to further understand the internal cultural environment, consolidate the internal cultural foundation, narrow the distance between China and Africa, help African economic recovery.

\section{OVERVIEW OF CROSS-CULTURAL MANAGEMENT RESEARCH}

Cross-cultural management refers to an effective management mode that coordinates different customs and traditions, ways of doing things and thinking habits under the multicultural background, so as to avoid or solve the cultural conflicts caused by cultural differences as far as possible, so as to improve the organizational performance and economic benefits of enterprises, and work together to achieve organizational goals [2]. Western countries were initially to study cross-cultural management, and formed some mature and typical theories. American anthropologists Florence Kluckhohn and Fred Strodtbeck (1961) formulated five value orientations: human nature, relationship of humankind to nature, sense of time, activity, and social relationships [3]. Hofstede $(1964,1989,2010)$ initially proposed four dimensions(Power Distance,Uncertainty Avoidance, 
Individualism versus Collectivism, Masculinity versus Femininity) that influence cultural differences to identify the influence of culture on organizational members' work attitudes and behaviors, and then gradually added two dimensions of "Long-term versus Short-term" and "Indulgence versus Restraint" to supplement and perfect the theory [4]; Fons Trompenaars $(1993,1998)$ put forward the theory of cultural structure, which holds that the cultural differences between countries and nations mainly reflect the individual and collective, universal and special, relationship-specific and diffuse, neutral and emotional, the relationship between human and nature, long-term and short-term orientation, and emphasis on individual achievement and social class [5]; Edward Hall (1976) divided the differences of cultural situations into two types: high context culture and low situational culture [6]. Many scholars in China have studied the cross-cultural management field from its causes and backgrounds and other factors to further explore the cross-cultural management mode in line with China's reality. The typical theory is CMC theory proposed by Professor Yu Wenzhao and Jia Yong (1997). Its connotation is that both parties of the joint venture constantly integrate the two cultures in the process of business operation in order to achieve higher economic benefits [7]; Professor Zhao Shuming (1997) put forward the problem of cultural differences of multinational corporations earlier, and pointed out that in the future, multinational corporations will face more severe cultural differences. The factors mainly come from three aspects: cultural differences are ubiquitous in crosscultural enterprises, cultural differences have continuity and stability, and people are the core of resource allocation. It is pointed out that the solution of cultural differences should rely on training to play a major role [8]; based on research of the former, Yan Liguang (2016) started from the essence of cross-cultural management, This paper summarizes the differences in cross-cultural management of Chinese enterprises, which are embodied in information differences, method differences and cultural differences, and puts forward four forms of cultural conflict [9].

\section{AN ANALYSIS OF THE CULTURAL DIFFERENCES BETWEEN CHINA AND AFRICA}

\subsection{Hofstede's cultural dimensions theory- based analysis}

There are many African countries with different enterprise nature and working environments, and the influence of cultural differences also shows diversity. However, the similar colonial development process and low degree of modernization in African countries lead to the common culture in some aspects. There are many similarities between Chinese and African cultures, such as emphasizing family values, respecting the old and loving the young, and tolerance. However, there are also obvious differences between Chinese and African cultures. Based on Hofstede's cultural dimensions theory, the differences between Chinese and African cultures are compared, as shown in Table 1 .

Table 1. Comparison of cultural differences between China and Africa

\begin{tabular}{l|ll}
\hline \multicolumn{1}{c|}{ Category } & \multicolumn{1}{c}{ China } & \multicolumn{1}{c}{ Africa } \\
\hline Power Distance & High power distance. & High power distance. \\
\hline $\begin{array}{l}\text { Individualism } \\
\text { /Collectivism }\end{array}$ & Collectivism & Individualism \\
\hline $\begin{array}{l}\text { Uncertainty } \\
\text { Avoidance }\end{array}$ & $\begin{array}{l}\text { High uncertainty } \\
\text { avoidance }\end{array}$ & $\begin{array}{l}\text { Low uncertainty } \\
\text { avoidance }\end{array}$ \\
\hline $\begin{array}{l}\text { Masculinization } \\
\text { Feminization }\end{array}$ & High feminization & High masculinity \\
\hline $\begin{array}{l}\text { Long-term/Short- } \\
\text { term }\end{array}$ & Long-term & Short-term \\
\hline $\begin{array}{l}\text { Indulgence } \\
\text { Restraint }\end{array}$ & $\begin{array}{l}\text { Strong social } \\
\text { constraints }\end{array}$ & $\begin{array}{l}\text { Weak social } \\
\text { constraints }\end{array}$ \\
\hline
\end{tabular}

\subsubsection{Power Distance}

Influenced by traditional Confucian culture, China has a high power distance; Africa, like most Asian countries, has a high power distance, which is more obvious among African governments and people with political status and political prestige.

\subsubsection{Individualism Verse Collectivism}

China advocates the values of "group orientation" as the core; many African countries have traditionally adopted tribal collectivism, but Africa has already changed its internal cultural pattern due to historical reasons, and individualism dominated by western culture has been inherited among African descendants. Therefore, African people value individualism more and pay more attention to the interests of individuals.

\subsubsection{Uncertainty Avoidance}

China has a high degree of uncertainty avoidance, and has a certain fear for the changing environment; African employees are generally not good at planning and summarizing, and like to let it go. They are more tolerant of different results caused by different behaviors, and are easily accepted with unknown risks and dare to take risks and attack.

\subsubsection{Masculinization Verse Feminization}

Chinese culture is more female; Africa's competitiveness is higher, that is, modesty is the embodiment of weakness; 
employees are confident and optimistic, more willing to implement, and highly masculine.

\subsubsection{Long-term Verse Short-term}

Chinese culture stresses on doing things in a long time, leaving room, saving and reserving, and focusing on the future, which has a typical long-term orientation; African people are naturally optimistic and more willing to "live in the present", which is the embodiment of the short-term orientation.

\subsubsection{Indulgence Verse Restraint}

China's social system, laws and regulations are perfect and meticulous, and they have greater binding force on individual citizens, and people can't do what they want; there are many African countries, and the systems of most African countries are not perfect, so the social binding force on people is insufficient, and people are more indulgent in themselves.

\subsection{Differences in employee behavior between China and Africa}

Through a large body of literature research and comparative analysis, the differences in employee behavior and management between China and Africa enterprises are mainly reflected in organizational communication, operation mode, ideology, management behavior and human resource management, as shown in Table 2.

Table 2. Comparison of differences in employee behavior between China and Africa

\begin{tabular}{|c|c|c|c|}
\hline \multicolumn{2}{|c|}{ Category } & \multirow{2}{*}{$\begin{array}{l}\text { Chinese Employees } \\
\text { Mainly in Chinese and English }\end{array}$} & \multirow{2}{*}{$\begin{array}{l}\text { African Employees } \\
\text { Arabic, English, French, etc }\end{array}$} \\
\hline $\begin{array}{l}\text { Organizational } \\
\text { Communication }\end{array}$ & Language & & \\
\hline \multirow{7}{*}{ Operation Mode } & Working attitude & High sense of responsibility & Value the completion of personal work \\
\hline & Working knowledge & Understand the overall work & Only focus on own work \\
\hline & Dealing with problems & Circuitous & Straightforward \\
\hline & Working article rationality & Work with a plan and purpose & Less grooming of work processes \\
\hline & In a difficult situation & Positive feedback and seek advice & Shy of asking for advice \\
\hline & Time sensitivity & Flexible & A strong sense of time \\
\hline & Summarize experience & More summary & Less summary \\
\hline \multirow{5}{*}{ Ideology } & Self-concept & Collective oriented & Individual oriented \\
\hline & Objective & Achieving organizational goals & Get personal benefits \\
\hline & Realize Measure & Pursue steadiness & Pursuing change \\
\hline & Expression & Euphemism & Outspoken \\
\hline & The concept of reputation & Value reputation & Value material \\
\hline \multirow{3}{*}{ Management Behavior } & Institutional awareness & Pay attention to the system & Lack of system \\
\hline & Decision-making method & Decision concentration & Decentralized decision making \\
\hline & Managerial style & Focus on process and results & Focus on results only \\
\hline \multirow{4}{*}{$\begin{array}{l}\text { Human Resource } \\
\text { Management }\end{array}$} & Recruitment & Internal and external recruitment & Mainly internal recruitment \\
\hline & Performance appraisal & Team-oriented & Individual-oriented \\
\hline & Salary management & Linked to personal performance & Linked to social factors \\
\hline & Training development & Focus on culture and basic ability & Focus on ability and skill improvement \\
\hline
\end{tabular}

\subsubsection{Organizational Communication}

Chinese often use Chinese or English to communicate. There are many African countries. Due to historical reasons, there are many languages widely used by African people, mainly English, French, and Arabic, etc.

\subsubsection{Operation Mode}

- Working attitude. Chinese employees are mostly dispatched to Africa, with high work ability and quality, and a high sense of responsibility. African employees are affected by education and other factors, and their technical skills are relatively weak, and their sense of responsibility for work is also relatively low.

- Working knowledge. Chinese employees attach importance to the cooperation between departments in their work, and they will understand the responsibilities of each department in addition to their own work responsibilities, so as to have a comprehensive understanding and grasp of work. Non party employees will pay more attention to 
themselves, pay attention to their own work, and have less information about other departments.

- Dealing with problems. Chinese employees are more flexible and will try to find a win-win method. Non employees are more simple and direct, and discuss the matter.

- Working article rationality. Chinese employees are good at making plans and setting the expected results in the process of work, and reflect and summarize the problems in the process of work after work, so as to finish work in a clear and orderly manner; non party employees are highly goal oriented, not paying attention to the process, paying more attention to the results, and not good at sorting out work.

- In a difficult situation. Chinese employees will try to solve problems by themselves. They like to consult others or give feedback to leaders about problems that can not be solved. Non party employees like to solve problems by themselves, and they are embarrassed to ask others for advice if they can't solve them.

- Time sensitivity. Chinese employees generally spend more time at work. Basically, the above company's opinions are mainly based on their own time. They think that their time is more flexible and they can actively work overtime to complete work. Nonworking employees clearly distinguish between work and personal time.

- Summarize experience. After completing a task, Chinese employees will reflect and summarize in a timely manner, and share their experience with colleagues. Non party employees do not like to summarize, and they think that experience summarized is their own and will not be shared with others.

\subsubsection{Ideology}

- Self concept. Chinese employees pay more attention to collective interests. When personal interests conflict with collective interests, they usually give up their personal interests in order to pursue higher collective interests. Non party employees are more individualistic and attach more importance to the interests brought to them by enterprises.

- Objective. Chinese employees are willing to contribute to the realization of organizational goals, while non Chinese employees seek to maximize their personal interests.

- Realize Measure. Chinese employees pursue steadiness in the process of achieving their goals and tend to adopt a conservative attitude when facing risks. Non Chinese employees are more adventurous and pursue change.

- Expression. Chinese employees will pay more attention to the face of their colleagues and leaders, and they will be euphemistic and implicit when expressing their personal opinions, while non Chinese employees will be more outspoken in the process of expressing their views, advocating the values of "I think what I say, I feel what I say".
- The concept of reputation. Chinese employees attach importance to face and reputation, and will sacrifice their rest time to work harder in order to gain the recognition of their superiors. Generally, non party employees think that reputation is not important, and their greatest expectation is to do their work well, and they will not pay attention to embarrassing things in their work.

\subsubsection{Management Behavior}

- Institutional awareness. In general, Chinese enterprises will use more rules and regulations to restrict their employees' behavior. System culture plays a great role in control. Employees have a strong system consciousness, while non Party's system is not perfect enough, and the employee's system awareness is weak.

- Decision-making method. China's decision-making is relatively concentrated in senior managers, and the decision-making process is relatively complex; nongovernmental decisions are made by individual employees, and leaders should be responsible for them, and the decision-making process stresses efficiency.

- Management style. In the process of management, the Chinese side pursues the effect and also pays great attention to the process of achieving results, that is, focusing on efficiency, so as to optimize the process; non party managers tend to be result oriented and generally do not interfere in the implementation process.

\subsubsection{Human Resource Management}

- Recruitment. The Chinese side will obtain talents through recruitment websites, campus recruitment, social recruitment, internal recommendation and other channels, and will focus on the age and work experience of the recruiters. The African side mainly relies on the internal recommendation of enterprises, and family nepotism is serious.

- Performance appraisal. The Chinese side focuses on the assessment of the team as a whole, while the African side focuses on the assessment of individual comprehensive ability.

- Salary management. The Chinese side will determine the salary level according to the working age, education level, qualifications and so on, and it is closely related to the personal work performance; the non Party's salary payment is mainly related to the external social environment, such as the price level, and generally does not adjust the salary due to the change of the employee's position.

- Training and development. The Chinese side will carry out various levels of training for employees, such as cultural knowledge, professional technology, management business, etc. Africa pays more attention to the training of personal skills, so that employees can be familiar with the work tasks in a short time. 


\section{PROBLEMS AND COUNTERMEASURES}

We can clearly distinguish the cultural differences between China and Africa from Hofstede's cultural dimensions theory, and at the same time, we can conclude six aspects of obvious differences in work behavior between Chinese and African enterprises. The influence of cultural differences on cross-cultural management of Chinese and African enterprises is multifaceted. In order to reduce or solve this influence, this article puts forward 5 guidance suggestions for reference.

\subsection{Problems}

\subsubsection{The conflict of management mode}

China's management model is generally characterized by centralized thinking and hierarchical organization. At the same time, the management process emphasizes flexible management, mainly qualitative, and pursues the "home" culture in the enterprise; some countries in Africa are influenced by Western culture. The management is relatively loose, with a flat organizational structure. The management process is mainly quantitative.

\subsubsection{The problems of human resource management}

According to table 2, there are significant differences between China and Africa in terms of recruitment, performance and salary management. In cross-cultural organizations, it is often difficult to establish a reasonable recruitment standard for employees that conforms to the values of both parties. In addition, different employees need to choose appropriate incentive methods. At the same time, in order to avoid unreasonable salary gaps, establish a standard that conforms to the actual situation A compensation plan that convinces both employees is necessary but not easy.

\subsubsection{The difficulty of Decision making and implementation}

Due to the differences in management concepts, business methods, and management models of the managers of Sino-African cooperative enterprises, the managers of the two parties often hold different opinions and opinions when making the company's strategic decisions, resulting in difficulties in unifying opinions, slow decision-making, and decision-making After reaching an agreement, there will be problems in the implementation of the decisionmaking process.

\subsubsection{The difficulty of staff cooperation}

Due to the differences in language problems, working methods and ideas, it is difficult for Chinese and African employees to achieve perfect cooperation and coordination when they jointly complete the same task.

\subsubsection{The difficulty of avoiding cognitive differences}

Some scholars learned from interviews with Chinesefunded companies in Tanzania that more than $90 \%$ of Chinese employers believe that local employees are unwilling to contribute to the company and often slack off work. At the same time, they believe that African employees are always dissatisfied with their wages. The overall evaluation of Fang employees is not high [10]. What I learned from local employees is that they are dissatisfied with the working environment provided by the company, low wages and long working hours, and believe that Chinese employers are squeezing their value.

\subsubsection{The difficulty of unifying Management System}

In Sino-African cooperative enterprises, employees of the two sides have very different working attitudes and working styles. For example, Chinese employees are tolerant of overtime, while non-employees are very strong in working overtime on workdays or at the expense of religious activities. To resist emotions, it is necessary to set up different working hours and vacation systems. Moreover, regarding the difference between collectivism and individualism in Chinese and African cultures, different assessment standards need to be divided for the same task. However, in cross-cultural organizations, it is often difficult to unify clear management systems (employee incentive system, employee evaluation system, and employee vacation system, etc.).

\subsection{Countermeasures}

\subsubsection{Understand and respect cultural differences}

First of all, enterprises should objectively understand the inevitability of cultural differences, and show understanding and respect for the behavior and values of employees with different cultural backgrounds. Secondly, employees are encouraged to learn from each other's customs and habits, behavior patterns and values of the two countries, learn from each other's excellent cultural achievements, find common points of convergence, and learn from each other's strengths to make up for their weaknesses, so as to carry out cross-cultural management 
more effectively. Finally, to allow employees to speak and express their opinions, enterprises should form a cultural atmosphere that both employees are willing to accept and accept, and create a multi-cultural integration.

\subsubsection{Carry out diversified training activities}

Carrying out diversified training activities is conducive to enhance comprehensive quality and skills of employees in the training activities, helping employees correctly understand cultural differences, adapt to and understand multiculture. Diversified cross-cultural management training activities can be divided into online and offline two parts, online learning and training are not limited by space and time, offline training activities have a strong learning atmosphere and strong experience, They can complement each other.

\subsubsection{Strengthen cross-cultural communication among employees}

The obstacles of cross-cultural communication mainly come from the deviation of thinking and cognition between employees, which leads to cultural conflicts. Conflicts can be resolved through continuous communication and communication. Effective communication is a bridge to build trust and cooperation between employees. Therefore, in the process of designing the organizational structure, it is necessary to establish and improve formal communication and feedback forms within the organization, and at the same time, build informal communication channels within the organization, so as to form a more open and inclusive communication environment.

\subsubsection{Optimize human resource management system}

First of all, it is necessary to formulate a sound and reasonable recruitment system. For employees with different cultural backgrounds, targeted recruitment should be carried out, and the abilities of the candidates should be investigated from various aspects. For example, the management personnel recruited should have certain management ability, language ability, ability to deal with conflicts, resolve contradictions, etc., and the grass-roots personnel recruited should have the correct attitude and learning ability, ensure the recruitment of employees meet the recruitment requirements of the enterprise. Secondly, improve the training system and carry out diversified training activities. Moreover, it is necessary to establish and improve the personnel system, formulate reasonable assessment standards and salary and welfare system in line with the cultural background of both sides, integrate into China's unique "family culture", give certain humanistic care to employees, and enhance the cohesion and appeal of the whole enterprise.

\subsubsection{Implement the talent localization strategy}

Enterprises can appropriately promote African local or internal excellent talents and old employees, give timely targeted training to help them adapt to their work, be good at employing people, dare to employ people and give them full trust. This is conducive to Sino-African cooperative enterprises to improve the recruitment, assessment and incentive of human resources, ensure the relative stability of personnel, reduce the negative impact of cultural differences on business operation, and improve the organizational performance of enterprises.

\section{CONCLUSION}

The differences in employee behavior and management between China and Africa are mainly reflected in five aspects: Organizational communication, Operation Mode, Ideology, Management behavior and Human resource management, There are six common cross-cultural management problems in Sino-African cooperative enterprises caused by cultural differences, such as the conflict of management mode, the problem of human resource management, the difficulty of decision-making and implementation, staff cooperation, and avoiding cognitive differences. In order to solve these problems, this research proposes five countermeasures: understand and respect cultural differences, carry out diversified training activities, strengthen cross-cultural communication among employees, optimize human resource management system, implement the talent localization strategy. This paper still has the following shortcomings: (1) only based on literature, referring to previous scholars' research data, without field investigation; (2) only from Hofstede's cultural dimensions theory to analyze the cultural differences between China and Africa. The future research direction can start from Edward's high and low cultural context framework and Trump Nel's theory of cultural structure to analyze the cultural differences between China and Africa, and can start with this theory to analyze more cultural differences between China and other countries; in the future, more first-hand research data should be added to ensure the effectiveness of the article.

\section{REFERENCES}

[1] Tang Xiaoyang. The issue of labor relations affects the overall situation of China-Africa diplomacy [C]. African Studies 2015 Vol. 1 (Total Vol. 6).: Institute of African Studies, Zhejiang Normal University, 2015: 203-215+297. (In Chinese)

[2] Hu Jun. Cross-cultural management [M]. Guangzhou: Jinan University Press, 1995(In Chinese) 
[3]Hills, Michael D. "Kluckhohn and Strodtbeck's Values Orientation Theory." Psychology and Culture. 4.4.(2001): 2-14. Web.DOI:

https://doi.org/10.9707/2307-0919.1040

[4] Hofstede (G.), Hofstede (Hofstede, GJ). Culture and Organization: The Power of Psychological Software [M]. 2nd edition. Li Yuan, Sun Jianmin. Translation. Beijing: Renmin University of China Press, 2010.

[5] Lu Wanqing. Cross-cultural management of tourism enterprises[M]. Nankai University Press, 2009. (In Chinese)

[6]Edward, H. Beyond Cultural[M].New York: Anchor Press, 1976.

[7] Yu Wenzhao, Jia Yong. The new model of co- management culture and its application $[\mathrm{J}]$. Applied Psychology, 1997(01): 3-10. (In Chinese)

[8] Zhao Shuming. Challenges faced by multinational companies in China: cultural differences and crosscultural management [J]. Management World, 1997(03): 76-81. (In Chinese)

[9] Yan Liguang. Research on the Nature of Crosscultural Management and the Response of Chinese Enterprises[J]. Henan Social Sciences, 2017, 25(03): 40-43. (In Chinese)

[10] Liu Ailan, Wang Zhixuan, Huang Meibo. Are cultural differences more important than institutional differences?: Empirical evidence from China's exports to Africa[J]. World Economic Research, 2018(10): 91107+137. (In Chinese) 